\title{
Accessory anterior ethmoidal nerve and artery: a cadaveric case report
}

\author{
D. Hage ${ }^{1}$, J. Iwanaga ${ }^{1-4}$, A. Danaei ${ }^{5}$, A. Sadr ${ }^{6}$, R.S. Tubbs' ${ }^{1,2,7-11}$ \\ ${ }^{1}$ Department of Neurosurgery, Tulane Centre for Clinical Neurosciences, Tulane University School of Medicine, \\ New Orleans, LA, United States \\ ${ }^{2}$ Department of Neurology, Tulane Centre for Clinical Neurosciences, Tulane University School of Medicine, \\ New Orleans, LA, United States \\ ${ }^{3}$ Dental and Oral Medical Centre, Kurume University School of Medicine, Kurume, Fukuoka, Japan \\ ${ }^{4}$ Division of Gross and Clinical Anatomy, Department of Anatomy, Kurume University School of Medicine, Kurume, \\ Fukuoka, Japan \\ ${ }^{5}$ University of British Columbia, Vancouver, Canada \\ ${ }^{6}$ Department of Restorative Dentistry, University of Washington School of Dentistry, Seattle, WA, United States \\ ${ }^{7}$ Department of Anatomical Sciences, St. George's University, St. George's, Grenada, West Indies \\ ${ }^{8}$ Department of Structural and Cellular Biology, Tulane University School of Medicine, New Orleans, LA, United States \\ ${ }^{9}$ Department of Surgery, Tulane University School of Medicine, New Orleans, LA, United States \\ ${ }^{10}$ Department of Neurosurgery and Ochsner Neuroscience Institute, Ochsner Health System, \\ New Orleans, LA, United States \\ ${ }^{11}$ University of Queensland, Brisbane, Australia
}

[Received: 2 December 2021; Accepted: 5 January 2022; Early publication date: 31 January 2021]

\begin{abstract}
The anterior ethmoidal artery (AEA) is an important surgical landmark for procedures involving the anterior cranial fossa. Many variations in the location and branching pattern of the AEA have been reported throughout the literature. These anatomical variations are important for surgeons to be familiar with as injury to the AEA can lead to massive haemorrhage, orbital haematomas, and cerebrospinal fluid rhinorrhoea. Anatomical landmarks such as the ethmoidal foramen can be used to identify the location of the AEA; however, it is also important to consider that the foramen may have variable presentations. If there is ever difficulty with identification of the AEA, surgeons should pursue a high-resolution computed tomography to minimise the risk of surgical complications. In this report, we present a rare case of a variant accessory anterior ethmoidal artery and nerve, and variations in the ethmoidal foramen found during cadaveric dissection. (Folia Morphol 2023; 82, 1: 183-186)
\end{abstract}

Key words: anterior ethmoidal artery, anterior ethmoidal nerve, anatomy, variations, orbit

\section{INTRODUCTION}

The anterior ethmoidal artery (AEA) is an important landmark to identify when performing surgeries that involve the anterior cranial fossa [3]. Injury to the AEA may cause the proximal segment to retract into the orbit resulting in an expanding bleeding within the intraconal space [9]. While variations have been reported, the AEA typically branches from the ophthalmic artery $(\mathrm{OA})$ lateral to the anterior ethmoidal foramen in the superomedial interconal space and the

Address for correspondence: J. Iwanaga, DDS, PhD, Department of Neurosurgery, Tulane Centre for Clinical Neurosciences, Tulane University School of Medicine, 131 S. Robertson St. Suite 1300, New Orleans, LA 70112, United States, tel: 5049885565, fax: 5049885793, e-mail: iwanagajoeca@gmail.com

This article is available in open access under Creative Common Attribution-Non-Commercial-No Derivatives 4.0 International (CC BY-NC-ND 4.0) license, allowing to download articles and share them with others as long as they credit the authors and the publisher, but without permission to change them in any way or use them commercially. 


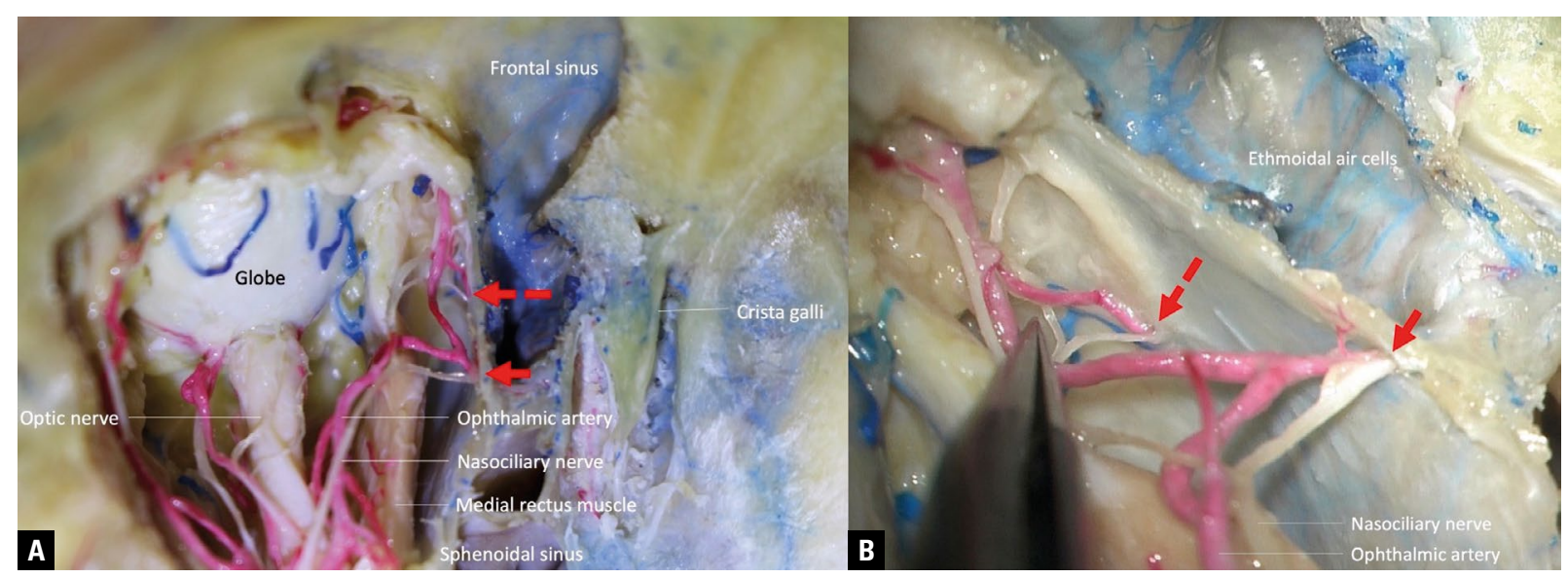

Figure 1. Normal and accessory ethmoidal arteries and nerves. Note that the anterior ethmoidal artery and nerve (both approximately $0.8 \mathrm{~mm}$ in diameter, arrow) and accessory ethmoidal artery and nerve (both approximately $0.4 \mathrm{~mm}$ in diameter, dotted arrow) enter the ethmoidal cells; A. Superior view of the left globe; B. Magnified oblique view of the left orbit.

anterior ethmoidal nerve branches from the nasociliary nerve [2]. These both exit the orbit through the anterior ethmoidal foramen [10] and follow a medial course along the anterior cranial fossa toward the cribriform plate [5]. Eventually, the AEA reaches the olfactory fossa and gives off its meningeal artery [16]. Additionally, the posterior ethmoidal artery runs between the superior oblique and the levator superioris muscles and supplies the posterior ethmoid cells, the upper nasal mucosa, and the meninges of the anterior cranial fossa [14]. Herein, we present a rare case of a variant accessory artery and nerve found during cadaveric dissection.

\section{CASE REPORT}

During the routine dissection of a cadaveric head of a Caucasian 72-year-old female at the time of death, a variant accessory artery and nerve (dotted arrow) were found anterior to the anterior ethmoidal foramen (arrow) in the left orbit (Fig. 1). The accessory nerve arose from the nasociliary nerve, and the accessory artery branched off the $O A$. The OA, nasociliary nerve, and their branches travelled superior to the medial rectus muscle. Both foramina connected to the ethmoidal cells. Neither one entered the sphenoidal sinus. There was no posterior ethmoidal foramen. The variant accessory foramen was not found on the right side. There were no previous surgical scars or other anatomical variations in the region dissected.

\section{DISCUSSION}

The AEA is at risk of injury from blunt trauma, endoscopic sinus surgery, and surgical interventions involving the inner wall of the orbit due to its course along the roof of the ethmoid from the orbit to the anterior cranial fossa $[1,4,11]$. Injury to the anterior and posterior ethmoid canals can lead to massive haemorrhage, orbital haematoma, or cerebrospinal fluid rhinorrhoea [4]. The AEA also plays an important role in the management of recurrent epistaxis as the septal branches are often implicated in cases of persistent epistaxis [16]. To quantify this, Turri-Zanoni et al. [16] performed endoscopic endonasal coagulation on 30 patients with epistaxis suspected to originate from the septal branches of the AEA. Among these patients, 16 did not have prior episodes of epistaxis, while 14 had an extensive history of refractory epistaxis [16]. The patients were followed up for a total of 19 months and only two of them were noted to have recurrent epistaxis; one of whom occurred at the 1-month follow-up and resolved following coagulation of the new site of the bleeding [16]. Surgeons need to be familiar with the location of the AEA and its branches as variations in its location and branching patterns may increase the risk of surgical complications.

Several anatomical studies have been conducted to better understand the variations of the ethmoidal arteries. Erdogmus et al. [4] analysed the orbits of 19 cadavers and were able to classify the branching patterns of the AEA into four different categories based on their anatomic relationship to the superior oblique muscle. They determined that the AEA could either branch medial (type 1) or lateral (type 2) to the lower segment of the superior oblique muscle, or branch medial (type 3) or lateral (type 4) to the 
upper segment of the superior oblique muscle [4]. In all 38 orbits analysed, the ethmoidal arteries originated from the $O A$ and eventually exited through the anterior ethmoidal foramen [4]. Similarly, Li et al. [10] demonstrated the AEA coursing beneath the superior oblique muscle and branching off the $O A$ lateral to the anterior ethmoidal foramen on all 16 sides of their 8 cadavers. However, in our current case, the accessory AEA and nerve were found anterior to the anterior ethmoidal foramen, rather than lateral to it. Additionally, the posterior ethmoidal artery is also susceptible to variation as Semmer et al. [14] reported that the posterior ethmoidal artery was absent in $15 \%$ of specimens where the OA crosses under the optic nerve and $19 \%$ of specimens when the OAs cross over the optic nerve. In our case, the clinical significance of the accessory AEA and nerve is unclear due to a lack of available literature. Alternative case reports, however, have documented examples of complications that can arise if there is an unknown variation in the anatomy of the AEA. For example, Wong et al. [17] reported the AEA emerging anteriorly to the bulla ethmoidalis rather than posterior to it in a patient with Waardenburg's syndrome. This only became evident after an inadvertent surgical injury to the AEA resulted in haemorrhage and retraction of the AEA into the orbit, leading to the development of a retrobulbar haematoma [17].

Furthermore, the ethmoidal foramina are also susceptible to variability. In our current case, the posterior ethmoidal foramen was absent, and the variant accessory foramen was not found on the right. Several studies have attempted to quantify the variability of the accessory ethmoidal foramen including Takahasi et al. [15] who investigated 54 orbits, across 27 Japanese cadavers. Among the orbits they analysed, $36(66.7 \%)$ had two ethmoidal foramina, 17 (31.5\%) had three foramina, and $1(1.9 \%)$ had one foramen [15]. They labelled the foramen based on their position between the anterior lacrimal crest and the optic canal (anterior, middle, deep middle, and, posterior) [15]. They found that 18 orbits (11 cadavers) were notable for the presence of an accessory foramen, with 17 of those orbits having one accessory foramen and 1 orbit having two accessory foramina [15]. Of the 11 cadavers, 4 (males) had unilateral foramen, 6 ( 3 males, 3 females) had bilateral foramen, and 1 (male) had one accessory foramen on the right and two accessory foramen on the left [15]. None of the cadavers included was notable for an absent anterior or posterior foramen as in our case. Similarly, Piagkou et al. [13] conducted a study analysing 249 orbits, across 137 Greek-Caucasian cadavers. Among their samples, $249(100 \%)$ orbits were notable for an anterior ethmoidal foramen, $245(98.4 \%)$ had a posterior ethmoidal foramen, and $68(27.3 \%)$ had a middle ethmoidal foramen [13]. They observed $4(1.6 \%)$ having an accessory foramen to the anterior ethmoidal foramen, $41(16.5 \%)$ with an accessory to the posterior ethmoidal foramen, and $3(1.2 \%)$ with an accessory to the middle ethmoidal foramen [13]. They further classified their cadavers into four categories based on the number of foramina observed: type 1 (4 orbits, $1.6 \%$ ) - a single anterior ethmoidal foramen, type 2 (152 orbits, 61\%) - an anterior and posterior ethmoidal foramina, type 3 (71 orbits, $28.5 \%$ ) - either an anterior, middle, and posterior foramina ( 46 orbits, $18.5 \%$ ), or an anterior and posterior foramina with an accessory to either ( 25 orbits, $10 \%$ ), and type 4 (19 orbits, $7.6 \%$ ) - with a range of 4-6 ethmoidal foramen [13].

\section{CONCLUSIONS}

Early identification and awareness of the anatomical variations in the AEA and ethmoidal foramen is important for surgeons to be aware of to reduce the risk of surgical complications. The use of landmarks to aid in the identification of the AEA has been extensively researched and several landmarks have been suggested such as the supraorbital ethmoid cells, nasal beak, nasal crest, and axilla of the middle turbinate $[7,12]$. Additionally, if the AEA is unidentifiable on a computed tomography scan, surgeons should pursue a repeat preoperative $\mathrm{CT}$ scan with a higher resolution, as this has been shown to better elucidate the location of the AEA [8].

\section{Acknowledgements}

The authors sincerely thank those who donated their bodies to science so that anatomical research could be performed. Results from such research can potentially increase mankind's overall knowledge that can then improve cadaver care. Therefore, these donors and their families deserve our highest gratitude [6].

Conflict of interest: None declared 


\section{REFERENCES}

1. Abdullah $B$, Lim EH, Husain $S$, et al. Anatomical variations of anterior ethmoidal artery and their significance in endoscopic sinus surgery: a systematic review. Surg Radiol Anat. 2019; 41(5): 491-499, doi: 10.1007/s00276-018-2165-3, indexed in Pubmed: 30542930.

2. Dallan I, Seccia V, Lenzi R, et al. Transnasal approach to the medial intraconal space: anatomic study and clinical considerations. Minim Invasive Neurosurg. 2010; 53(04): 164-168, doi: 10.1055/s-0030-1263106.

3. de Almeida JR, Snyderman CH, Gardner PA, et al. Nasal morbidity following endoscopic skull base surgery: a prospective cohort study. Head Neck. 2011; 33(4): 547-551, doi: 10.1002/hed.21483, indexed in Pubmed: 20824807.

4. Erdogmus S, Govsa F. The anatomic landmarks of ethmoidal arteries for the surgical approaches. J Craniofac Surg. 2006; 17(2): 280-285, doi: 10.1097/00001665200603000-00014, indexed in Pubmed: 16633176.

5. Hwang $\mathrm{SH}$, Joo $\mathrm{YH}$, Seo JH, et al. Endoscopic endonasal approach of the medial intraconal space: CT analysis of the anatomic relation between paranasal structures and orbital contents. J Craniofac Surg. 2012; 23(4): 966-969, doi: 10.1097/SCS.0b013e31824e5c7f, indexed in Pubmed: 22777448.

6. Iwanaga J, Singh V, Ohtsuka A, et al. Acknowledging the use of human cadaveric tissues in research papers: recommendations from anatomical journal editors. Clin Anat. 2021; 34(1): 2-4, doi: 10.1002/ca.23671, indexed in Pubmed: 32808702.

7. Jang DW, Lachanas VA, White LC, et al. Supraorbital ethmoid cell: a consistent landmark for endoscopic identification of the anterior ethmoidal artery. Otolaryngol Head Neck Surg. 2014; 151(6): 1073-1077, doi: 10.1177/0194599814551124, indexed in Pubmed: 25257902.

8. Lannoy-Penisson L, Schultz P, Riehm S, et al. The anterior ethmoidal artery: radio-anatomical comparison and its application in endonasal surgery. Acta Otolaryngol. 2007; 127(6): 618-622, doi: 10.1080/00016480600987826, indexed in Pubmed: 17503231.

9. Lenzi R, Bleier BS, Felisati G, et al. Purely endoscopic trans-nasal management of orbital intraconal cavernous haemangiomas: a systematic review of the literature. Eur Arch Otorhinolaryngol. 2016; 273(9): 2319-2322, doi: 10.1007/s00405-015-3733-3, indexed in Pubmed: 26210157.

10. Li L, London NR, Prevedello DM, et al. Intraconal anatomy of the anterior ethmoidal neurovascular bundle: implications for surgery in the superomedial orbit. Am J Rhinol Allergy. 2020; 34(3): 394-400, doi: 10.1177/1945892420901630, indexed in Pubmed: 31973546.

11. Ohnishi T, Tachibana T, Kaneko $Y$, et al. High-risk areas in endoscopic sinus surgery and prevention of complications. Laryngoscope. 1993; 103(10): 1181-1185, doi: 10.1288/00005537-199310000-00020, indexed in Pubmed: 8412459.

12. Pernas FG, Coughlin AM, Hughes SE, et al. A novel use of a landmark to avoid injury of the anterior ethmoidal artery during endoscopic sinus surgery. Am J Rhinol Allergy. 2011; 25(1): 54-57, doi: 10.2500/ajra.2011.25.3541, indexed in Pubmed: 21711980.

13. Piagkou M, Skotsimara G, Dalaka A, et al. Bony landmarks of the medial orbital wall: an anatomical study of ethmoidal foramina. Clin Anat. 2014; 27(4): 570-577, doi: 10.1002/ca.22303, indexed in Pubmed: 24000039.

14. Semmer AE, McLoon LK, Lee MS. Orbital vascular anatomy. In: Encycloedia of the eye. Dartt DA (ed.). Academic Press, Oxford 2010: 241-251.

15. Takahashi $Y$, Kakizaki H, Nakano T. Accessory ethmoidal foramina: an anatomical study. Ophthalmic Plast Reconstr Surg. 2011; 27(2): 125-127, doi: 10.1097/ IOP.0b013e318201c8fd, indexed in Pubmed: 21224747.

16. Turri-Zanoni M, Arosio AD, Stamm AC, et al. Septal branches of the anterior ethmoidal artery: anatomical considerations and clinical implications in the management of refractory epistaxis. Eur Arch Otorhinolaryngol. 2018; 275(6): 1449-1456, doi: 10.1007/s00405-018-4964-x, indexed in Pubmed: 29600317.

17. Wong DKC, Shao A, Campbell R, et al. Anterior ethmoidal artery emerging anterior to bulla ethmoidalis: An abnormal anatomical variation in Waardenburg's syndrome. Allergy Rhinol (Providence). 2014; 5(3): 168-171, doi: 10.2500/ar.2014.5.0094, indexed in Pubmed: 25565054. 